\title{
Patient-reported outcomes for axitinib vs sorafenib in metastatic renal cell carcinoma: phase III (AXIS) trial
}

\author{
D Cella ${ }^{*}, 1$, B Escudier ${ }^{2}$, B Rini ${ }^{3}$, C Chen ${ }^{4}, \mathrm{H}$ Bhattacharyya ${ }^{4}, \mathrm{~J} \mathrm{Tarazi}^{5}$, B Rosbrook ${ }^{5}, \mathrm{~S} \mathrm{Kim}{ }^{5}$ and R Motzer ${ }^{6}$
}

${ }^{1}$ Department of Medical Social Sciences, Northwestern University Feinberg School of Medicine, 633 N. St, Clair - 19th Floor Chicago, IL 60611, USA; ${ }^{2}$ Department of Medicine, Institut Gustave Roussy, 39 rue Camille Desmoulins, Villejuif Cedex 94805, France; ${ }^{3}$ Solid Tumor Oncology, The Cleveland Clinic Taussig Cancer Institute, 9500 Euclid Avenue, Cleveland, OH 44195, USA; ${ }^{4}$ Global Outcomes Research, Pfizer Inc, 235 East 42nd Street, New York, NY 10017, USA; ${ }^{5}$ Pfizer Oncology, 10646 Science Center Drive, La Jolla, San Diego, CA 92121, USA and ' ${ }^{6}$ epartment of Medicine, Memorial Sloan-Kettering Cancer Center, 1275 York Avenue, New York, NY 10065, USA

Background: Axitinib demonstrated greater progression-free survival vs sorafenib in a phase III study of previously treated patients with metastatic renal cell carcinoma. Here, we report patient-reported kidney-specific symptoms and health status, measured by the Functional Assessment of Cancer Therapy (FACT) Kidney Cancer Symptom Index (FKSI) and the European Quality of Life self-report questionnaire (EQ-5D).

Methods: In all, 723 patients received axitinib (starting dose $5 \mathrm{mg}$ twice daily (b.i.d.)) or sorafenib (400 mg b.i.d.). The FKSI-15, including the disease-related symptoms (FKSI-DRS) subscale, was administered on day 1 before dosing, every 4 weeks and at end of treatment (EOT)/withdrawal. Statistical methods included a mixed-effects repeated-measures model.

Results: At baseline, patients in both arms had relatively high mean FSKI-15 and FKSI-DRS scores, comparable to the general US population. Subsequent on-treatment overall mean scores were similar between axitinib and sorafenib, and there was no substantial decline during treatment. Scores substantially worsened at EOT, mainly due to disease progression.

Conclusion: Patient-reported outcomes were comparable for second-line axitinib and sorafenib and were maintained at relatively high levels while on treatment, but worsened at EOT. As duration of treatment was longer with axitinib than sorafenib, time to worsening of symptoms can be delayed longer with axitinib.

Patients with metastatic renal cell carcinoma (mRCC) typically experience cancer-related symptoms and impaired health-related quality of life (HRQoL) that significantly impact daily functioning and limit therapy (Harding et al, 2007; Gupta et al, 2008; Cella,
2009). Furthermore, the impact of symptoms and treatment-related toxicity on HRQoL is often underestimated (Harding et al, 2007; Gupta et al, 2008; Cella, 2009). Measurement of HRQoL outcomes provides information on the effect of treatment (Wagner et al, 2007)

*Correspondence: Dr D Cella, E-mail: d-cella@northwestern.edu

Prior presentation: The work presented in this manuscript is original and has not been published elsewhere. Portions of the data have previously been presented as listed below.

(1) D Cella, B Escudier, BI Rini, et al. Patient-reported outcomes (PROs) in a phase III AXIS trial of axitinib versus sorafenib as second-line therapy for metastatic renal cell carcinoma (mRCC). Oral presentation at American Society of Clinical Oncology Annual Meeting, Chicago, IL, USA, 3-7 June 2011. (2) D Cella, B Escudier, B Rini et al. Time to deterioration (TTD) in patient-reported outcomes in phase 3 AXIS trial of axitinib vs sorafenib as secondline therapy for metastatic renal cell carcinoma (mRCC). Poster presentation at European Society for Medical Oncology 36th Congress-ECCO 16 and ESMO 36, Stockholm, Sweden, 23-27 September 2011.

Received 21 November 2012; revised 1 March 2013; accepted 7 March 2013; published online 11 April 2013

(c) 2013 Cancer Research UK. All rights reserved 0007-0920/13 
and assists the evaluation of the trade-off between extended progression-free survival (PFS) and treatment toxicity that, given disease progression rates following first-line treatment failure, is particularly relevant for second-line therapies.

Metastatic RCC is difficult to treat (Lam et al, 2004); without effective treatment patients often die in $<2$ years (Linehan and Zbar, 2004). The disease is often resistant to chemotherapy, but targeted treatments, including tyrosine kinase inhibitors (TKIs; sunitinib (Motzer et al, 2007), sorafenib (Escudier et al, 2007a, 2009), pazopanib (Sternberg et al, 2010)), the vascular endothelial growth factor (VEGF) monoclonal antibody bevacizumab (Escudier et al, 2007b) and temsirolimus and everolimus (inhibitors of the mammalian target of rapamycin pathway) (Hudes et al, 2007; Motzer et al, 2008, 2010), have demonstrated clinical benefit in these patients.

Axitinib is a potent and selective second-generation inhibitor of VEGF receptors (VEGFR)-1, 2, and 3 (Hu-Lowe et al, 2008). Phase II studies demonstrated clinical activity in patients with advanced RCC refractory to cytokines (Rixe et al, 2007) or sorafenib (Rini et al, 2009). In a randomised phase III clinical trial (AXIS) that compared the efficacy and safety of axitinib with sorafenib in patients with advanced RCC with disease progression after firstline systemic therapy, median PFS for axitinib was 6.7 months vs 4.7 months for sorafenib (hazard ratio $(\mathrm{HR})=0.665 ; P<0.0001$ ) (Rini et al, 2011). Results for the composite end point of time-totreatment deterioration (TTD; defined as a decrease in quality of life (worsening of Functional Assessment of Cancer Therapy (FACT) Kidney Symptom Index-15 (FKSI-15) score), progression or death; see Rini et al (2011) and Amir et al (2012) for further details) were also reported, but an overall assessment of HRQoL was not.

This report summarises the effect of axitinib vs sorafenib on patient-reported kidney cancer-specific symptoms/functioning and health status, which were secondary end points of the phase III study.

\section{MATERIALS AND METHODS}

Study design and patients. The pre-specified patient-reported outcome end point analyses were derived from a prospective, open-label, randomised phase III clinical trial in patients with advanced RCC after failure of one first-line systemic regimen, details of which have been reported elsewhere (Rini et al, 2011). Briefly, eligible patients were stratified according to Eastern Cooperative Oncology Group (ECOG) performance status (0 or 1) and prior therapy (sunitinib-, bevacizumab/interferon (IFN)- $\alpha$-, temsirolimus-, or cytokine-based regimens) and randomised $(1: 1)$ to axitinib or sorafenib. Inclusion criteria included age $\geqslant 18$ years; histologically or cytologically confirmed RCC with a clear cell component; measurable disease per Response Evaluation Criteria in Solid Tumours (RECIST) (Therasse et al, 2000); and $\geqslant 2$ weeks since the end of prior systemic treatment or $\geqslant 4$ weeks for bevacizumab/IFN- $\alpha$ treatment. Patients were excluded if they had central nervous system metastasis; uncontrolled hypertension (blood pressure (BP) $\geqslant 140 / 90 \mathrm{~mm} \mathrm{Hg}$ ); clinically significant cardiovascular disease or events within 12 months before study drug administration; or deep vein thrombosis or pulmonary embolism within 6 months.

The trial was approved by an institutional review board or ethics committee at each centre and complied with Good Clinical Practice guidelines, the Declaration of Helsinki, and local laws. All patients provided written informed consent. The trial is registered on ClinicalTrials.gov, identifier NCT00678392.

Treatment regimens. Axitinib was administered orally at a starting dose of $5 \mathrm{mg}$ twice daily (b.i.d.). Patients who tolerated this dose with no significant treatment-related grade $>2$ adverse reactions for a 2-week period had their dose increased to $7 \mathrm{mg}$ b.i.d., unless BP was $>150 / 90 \mathrm{~mm} \mathrm{Hg}$ or they were receiving antihypertensive medication. Using the same criteria, patients who tolerated $7 \mathrm{mg}$ b.i.d. had their dose increased to a maximum of $10 \mathrm{mg}$ b.i.d. Axitinib dose reductions were allowed for management of toxicity. The sorafenib starting dose was $400 \mathrm{mg}$ b.i.d., which could be reduced to $400 \mathrm{mg}$ once daily or $400 \mathrm{mg}$ every other day to manage toxicity. Patients were treated until disease progression (per RECIST criteria, version 1.0; Therasse et al, 2000), occurrence of unacceptable toxicity or death or withdrawal of consent.

Patient-reported outcome measures. Patient-reported outcomes were assessed using the FKSI-15 (Cella et al, 2006) and the EuroQoL (EQ-5D) (Kind, 1996), and were completed at screening, after every 4 weeks of therapy, at end of study treatment, and at follow-up (28 days after end of therapy). End of treatment (EOT) and follow-up data were collected at different cycles, reflecting the different times that patients went off treatment. To avoid potential bias, questionnaires were completed before patients discussed their disease status with health-care professionals. The FKSI-15 includes 15 items: lack of energy, bothered by side effects, pain, weight loss, bone pain, fatigue, enjoyment of life, shortness of breath, worry condition may worsen, appetite, coughing, bothered by fevers, ability to work, haematuria, and sleeping well. In this trial, two scores-the FKSI-15 total score and the FKSI-Disease-Related Symptoms (FKSI-DRS) score-were derived. The FKSI-DRS is a 9-item subscale of FKSI-15 that includes lack of energy, pain, weight loss, bone pain, fatigue, shortness of breath, coughing, bothered by fevers, and haematuria (Cella et al, 2007). Each question was answered on a 5-point Likert-type scale ranging from 0 to $4(0=$ not at all; $1=$ a little bit; $2=$ somewhat; $3=$ quite a bit; $4=$ very much). The FKSI-15 score (range $0-60$ ) is the sum of the 15 individual items, and the FKSI-DRS score (range 0-36) is the sum of its 9 individual item scores. For some questions, answers were the item scores; for other questions, answers were reverse coded such that higher scores corresponded to better HRQoL and fewer symptoms. If answers to individual questions were missing, then scores were calculated as the pro-rated sum of the nonmissing items (provided $>50 \%$ of the questions, e.g., at least 8 of 15 for FKSI-15, were answered). Both the FKSI-15 and FKSI-DRS have been validated in patients with kidney cancer (Cella et al, 2006, 2007). An important difference was estimated to be 3-5 points for the FKSI-15 scale (range 0-60) (Cella et al, 2006) and 2-3 points for the FKSI-DRS (range 0-36) subscale (Cella et al, 2007).

The EQ-5D is a preference-based generic health status measure and comprises two components, an index score with five items (mobility, self-care, usual activities, pain/discomfort, and anxiety/ depression) and a visual analogue scale score for overall health state (Kind, 1996). For this study, we used the index scoring algorithm derived from a UK general population sample (Kind, 1996).

Statistical analysis. All analyses were performed on the intent-totreat population. Descriptive statistics were used to summarise demographic and clinical characteristics and patient-reported outcome scores by treatment arm. Comparisons of post-treatment scores were performed using a repeated-measures mixed-effects model, including terms for treatment, time and treatment-by-time, with baseline as covariate and time assumed continuous (Singer and Willett, 2003; Hedeker and Gibbons, 2006). This model permits multiple observations at different time points, but assumes missing values are missing at random. To account for the possibility of data missing not at random (Rubin, 1976; Troxel et al, 1998) (e.g., variation in missing values due to treatment), pattern mixture models were explored as a sensitivity analysis. All available data were used in these analyses. 


\section{RESULTS}

Baseline characteristics. In all, 723 patients were assigned to axitinib $(n=361)$ or sorafenib $(n=362)$ treatment. Baseline characteristics have been described previously (Rini et al, 2011). Baseline demographic and clinical characteristics, as well as baseline FKSI-15 and FKSI-DRS scores, were similar between treatment arms (Table 1) (Motzer et al, 2004; Heng et al, 2009).

Dose modifications. During treatment, 199 (55.4\%) and 220 (62.0\%) patients had at least one dose interruption due to adverse events in the axitinib and sorafenib arms, respectively, and 95 $(26.5 \%)$ and $73(20.6 \%)$ patients had at least one dose reduction due to adverse events in the axitinib and sorafenib arms, respectively.

Patient-reported outcome completion rates. The patientreported outcome completion rate was $>85 \%$ at baseline, and for the majority of the study $90 \%$ or more eligible patients contributed to the patient-reported analyses at each cycle. The number of eligible patients was higher in the axitinib vs sorafenib arm due to varying dropout rates resulting from differential rates of disease progression (e.g., by cycle $8,52.1 \%$ of patients in the axitinib arm were eligible compared with $40.1 \%$ in the sorafenib arm). At EOT, in both treatment arms, the majority of patients who had stopped treatment had done so because of disease progression, with adverse events accounting for $10.0 \%$ and $12.9 \%$ of cases in the axitinib and sorafenib arms, respectively.

FKSI assessments. Observed FKSI-15 means and corresponding sample sizes for the axitinib and sorafenib arms are shown in Figure 1. Mean values for axitinib and sorafenib were almost identical at baseline (43.20 and 43.34, respectively; Table 1 ) and remained similar throughout the study. The FKSI-15 scores for both treatments worsened (dropped) at EOT (axitinib, 38.33; sorafenib, 38.46). End of treatment was, in the majority of cases, triggered by disease progression. Mean values for 28-day follow-up were 41.92 and 40.03 in the axitinib and sorafenib arms, respectively, which were somewhat higher than the respective values at EOT; however, compliance at this time point had dropped to $\sim 40 \%$ in both treatment arms. To examine if there was a responder bias, all end-of-treatment data from patients in both treatment arms were combined and divided into two groups; those with $(n=169)$ and those without $(n=194)$ follow-up (day 28) data. Patients with follow-up data had a significantly higher mean FKSI-15 score at EOT than those without (40.15 vs 37.01, respectively; difference, $3.14 ; P=0.0009)$. Furthermore, the mean FKSI-15 score at EOT for patients with follow-up was almost identical to their mean score at follow-up (40.15 and 40.81, respectively), suggesting that healthier patients were the ones contributing to the 28-day follow-up scores.

No statistically significant differences between axitinib and sorafenib were observed using a repeated measures mixed-effects model. Post-treatment least squares means were 42.21 and 41.86 for axitinib and sorafenib, respectively $(P=0.4833$; Table 2$)$. There was no significant interaction between treatment and time $(P=0.3943)$, indicating no difference in the course of the treatment effect over the cycles.

The mixed-effects analysis was also performed for each of the individual items of the FKSI-15. No significant treatment effect was observed for any item (Table 3). Owing to the differential dropout rates between the two treatment arms, a pattern-mixture analysis was performed as a sensitivity analysis. Two patterns were defined: completers (patients completing $>168$ days (6 cycles) of treatment) and dropouts (those completing 168 or fewer days of treatment). A threshold of six cycles was chosen, as this was the last cycle in which over $50 \%$ of patients in both treatment arms
Table 1. Baseline characteristics ${ }^{a}$

\begin{tabular}{|c|c|c|}
\hline & Axitinib & Sorafenib \\
\hline Variable & $n=361$ & $n=362$ \\
\hline Age, years, median (range) & $61(20-82)$ & $61(22-80)$ \\
\hline \multicolumn{3}{|l|}{ Gender } \\
\hline $\begin{array}{l}\text { Male } \\
\text { Female }\end{array}$ & $\begin{array}{c}265(73) \\
96(27)\end{array}$ & $\begin{array}{l}258(71) \\
104(29)\end{array}$ \\
\hline \multicolumn{3}{|l|}{ Race } \\
\hline $\begin{array}{l}\text { White } \\
\text { Black } \\
\text { Asian } \\
\text { Other }\end{array}$ & $\begin{array}{c}278(77) \\
1(<1) \\
77(21) \\
5(1)\end{array}$ & $\begin{array}{c}269(74) \\
4(1) \\
81(22) \\
8(2)\end{array}$ \\
\hline \multicolumn{3}{|c|}{ ECOG performance status } \\
\hline $\begin{array}{l}0 \\
1 \\
>1\end{array}$ & $\begin{array}{l}195(54) \\
162(45) \\
1(<1)^{b}\end{array}$ & $\begin{array}{c}200(55) \\
160(44) \\
0\end{array}$ \\
\hline
\end{tabular}

MSKCC risk group ${ }^{c}$ (Motzer et al, 2004)

\begin{tabular}{|l|c|c|}
\hline 0 (favourable) & $100(28)$ & $101(28)$ \\
$1-2$ (intermediate) & $134(37)$ & $130(36)$ \\
$\geqslant 3$ (poor) & $118(33)$ & $120(33)$ \\
NA & $9(2.5)$ & $11(3.0)$ \\
\hline
\end{tabular}

Heng et al risk factors (Heng et al, 2009)

\begin{tabular}{|l|c|c|}
\hline 0 (favourable) & $66(18)$ & $79(22)$ \\
$1-2$ (intermediate) & $236(65)$ & $225(62)$ \\
$\geqslant 3$ (poor) & $37(10)$ & $34(9)$ \\
N/A & $22(6)$ & $24(7)$ \\
\hline
\end{tabular}

Prior systemic therapy

\begin{tabular}{|l|c|c|}
\hline Sunitinib & $194(54)$ & $195(54)$ \\
Cytokines & $126(35)$ & $125(35)$ \\
Bevacizumab & $29(8)$ & $30(8)$ \\
Temsirolimus & $12(3)$ & $12(3)$ \\
\hline
\end{tabular}

Baseline FKSI-15 score

\begin{tabular}{|l|c|c|}
\hline $\mathbf{N}$ & 346 & 342 \\
Observed mean (s.d.) & $43.20(8.42)$ & $43.34(8.16)$ \\
\hline
\end{tabular}

Baseline FKSI-DRS score

\begin{tabular}{|l|c|c|}
\hline $\mathbf{N}$ & 346 & 341 \\
Observed mean (s.d.) & $28.87(5.19)$ & $28.98(5.19)$ \\
\hline
\end{tabular}

Abbreviations: $\mathrm{ECOG}=$ Eastern Cooperative Oncology Group; FKSI = Functional Assessment of Cancer Therapy Kidney Symptom Index; FKSI-DRS=Functional Assessment of Cancer Therapy Kidney Symptom Index-Disease-Related Symptoms; MSKCC = Memorial Sloan-Kettering Cancer Center; s.d. = standard deviation.

${ }^{a}$ Values are $n(\%)$ unless otherwise noted.

brotocol violation.

${ }^{c}$ MSKCC risk groups were derived using three risk factors: haemoglobin ( $\leqslant 13 \mathrm{vs}>13 \mathrm{~g} \mathrm{dl}^{-1}$ for males and $\leqslant 11.5 \mathrm{vs}>11.5 \mathrm{~g} \mathrm{dl}^{-1}$ for females), 'corrected' calcium ( $\left.<10 \mathrm{vs} \geqslant 10 \mathrm{mg} \mathrm{dl}^{-1}\right)$ and ECOG performance status ( 0 vs 1 ). Risk groups were defined as favourable ( 0 factors), intermediate ( 1 factor), or poor (2-3 factors).

remained in the study. Results were similar to those of the standard mixed-effects model. A pattern-mixture analysis was also performed based on three patterns where the thresholds were study days 84 and 196 (i.e., end of cycles 3 and 8 upon completion of radiologic determinations of tumour progression). Again, there was no significant difference between the treatment arms.

There was no significant treatment difference in FKSI-15 scores for patients who had received prior sunitinib or patients who 


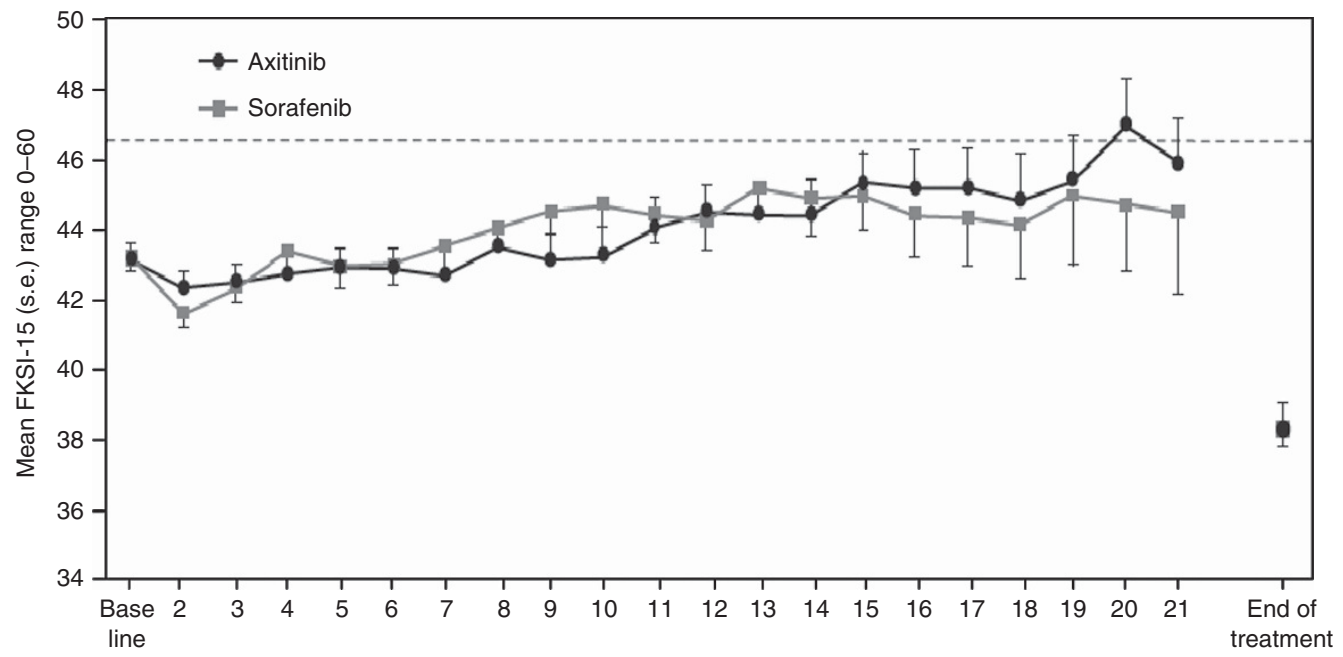

Cycles

\begin{tabular}{lllllllllllllllllllllll}
\hline Axitinib & 346 & 319 & 279 & 257 & 238 & 213 & 206 & 177 & 163 & 146 & 122 & 110 & 92 & 81 & 61 & 52 & 47 & 36 & 29 & 20 & 15 & 163 \\
\hline Sorafenib & 342 & 296 & 246 & 221 & 203 & 179 & 158 & 136 & 118 & 96 & 85 & 70 & 58 & 54 & 38 & 34 & 28 & 22 & 14 & 12 & 7 & 191 \\
\hline
\end{tabular}

Figure 1. Mean FKSI-15 scores over the course of the study. Dotted line represents US population mean. Point estimates for end of treatment scores for axitinib and sorafenib arms are virtually identical and therefore indistinguishable. FKSI-15, Functional Assessment of Cancer Therapy Kidney Symptom Index-15; s.e., standard error.

\section{Table 2. Treatment differences for PRO instruments}

\begin{tabular}{|c|c|c|c|c|c|}
\hline \multicolumn{6}{|c|}{ Estimated mean } \\
\hline Instrument & $\begin{array}{l}\text { Axitinib } \\
(n=361)\end{array}$ & $\begin{array}{l}\text { Sorafenib } \\
(n=362)\end{array}$ & Difference & $95 \% \mathrm{Cl}$ & $P$-value \\
\hline \multicolumn{6}{|l|}{ FKSI-15 } \\
\hline $\begin{array}{l}\text { Treatment } \\
\text { Treatment-by-time }\end{array}$ & 42.21 & 41.86 & 0.35 & $-0.63,1.34$ & $\begin{array}{l}0.4833 \\
0.3943\end{array}$ \\
\hline \multicolumn{6}{|l|}{ FKSI-DRS } \\
\hline $\begin{array}{l}\text { Treatment } \\
\text { Treatment-by-time }\end{array}$ & 28.56 & 28.44 & 0.12 & $-0.45,0.69$ & $\begin{array}{l}0.6746 \\
0.8024\end{array}$ \\
\hline \multicolumn{6}{|l|}{ EQ-5D } \\
\hline $\begin{array}{l}\text { Treatment } \\
\text { Treatment-by-time }\end{array}$ & 0.71 & 0.69 & 0.02 & $-0.01,0.05$ & $\begin{array}{l}0.1903 \\
0.8048\end{array}$ \\
\hline \multicolumn{6}{|l|}{ EQ-5D VAS } \\
\hline $\begin{array}{l}\text { Treatment } \\
\text { Treatment-by-time }\end{array}$ & 68.11 & 68.64 & -0.53 & $-2.77,1.72$ & $\begin{array}{l}0.6454 \\
0.1799\end{array}$ \\
\hline
\end{tabular}

Abbreviations: $\mathrm{Cl}=$ confidence interval; FKSI-15 = Functional Assessment of Cancer Therapy Kidney Symptom Index-15; FKSI-DRS = Functional Assessment of Cancer Therapy Kidney Symptom Index-Disease-Related Symptoms; PRO = patient-reported outcomes; VAS = visual analogue scale. Analysis based on repeated measures mixed-effects model with terms for treatment, time, and treatment-by-time, with baseline as covariate and time assumed continuous. Larger values correspond to better health states. Individual FKSI items may be reverse coded, as appropriate.

received prior cytokine therapy based on the mixed-effects analysis. Baseline scores were similar for both treatments in both subgroups (prior sunitinib-axitinib arm 42.68; sorafenib arm 42.97; prior cytokines-axitinib arm 44.04; sorafenib arm 44.54). Scores in both subgroups remained similar throughout treatment and worsened at EOT (prior sunitinib-axitinib arm 36.86; sorafenib arm 37.15; prior cytokines-axitinib arm 40.30; sorafenib arm 40.32). Analysis by MSKCC risk subgroup (favourable, intermediate, poor) also showed no significant treatment difference in any of the MSKCC subgroups. The difference in the risk groups was reflected in the baseline scores (favourable-axitinib arm 46.89; sorafenib arm 47.47; intermediate-axitinib arm 43.20; sorafenib arm 43.23; pooraxitinib arm 40.44; sorafenib arm 39.83).
FKSI-DRS assessments. The mixed-effects analysis of FKSI-DRS scores revealed results similar to those for FKSI-15, with no significant difference between the treatment arms (Figure 2). Mean FKSI-DRS values for axitinib and sorafenib were similar throughout the study. Baseline values (28.87 and 28.98, respectively; Table 1) were maintained throughout the study, but scores worsened at EOT (26.29 and 26.52, respectively). Mean values for 28-day follow-up were 28.26 and 27.52 , respectively. Similar to the FKSI-15 analysis of responder status at EOT, FKSI-DRS mean scores for patients who provided follow-up data were higher than those who did not (27.32 and 25.67, respectively; difference, 1.66; $P=0.0050$ ).

There was no statistically significant difference in the posttreatment difference between axitinib and sorafenib based on the 
Estimated mean

\begin{tabular}{|c|c|c|c|c|c|}
\hline Item & Axitinib $(n=361)$ & Sorafenib $(n=362)$ & Difference & $95 \% \mathrm{Cl}$ & $P$-value \\
\hline 1. I have a lack of energy & 1.52 & 1.50 & 0.03 & $-0.09,0.15$ & 0.6627 \\
\hline $\begin{array}{l}\text { 2. I am bothered by side effects of } \\
\text { treatment }\end{array}$ & 1.43 & 1.53 & -0.11 & $-0.25,0.04$ & 0.1399 \\
\hline 3. I have pain & 1.14 & 1.19 & -0.05 & $-0.18,0.08$ & 0.4752 \\
\hline 4. I am losing weight & 0.81 & 0.83 & -0.02 & $-0.14,0.10$ & 0.7724 \\
\hline 5. I have bone pain & 0.75 & 0.72 & 0.03 & $-0.10,0.15$ & 0.6782 \\
\hline 6. I feel fatigued & 1.44 & 1.43 & 0.01 & $-0.11,0.13$ & 0.9157 \\
\hline 7. I am able to enjoy life & 2.27 & 2.39 & -0.12 & $-0.25,0.02$ & 0.0925 \\
\hline 8. I have been short of breath & 0.87 & 0.88 & -0.01 & $-0.11,0.10$ & 0.9219 \\
\hline 9. I worry that my condition will get worse & 1.44 & 1.55 & -0.11 & $-0.24,0.02$ & 0.0918 \\
\hline 10. I have a good appetite & 2.05 & 2.09 & -0.04 & $0.18,0.11$ & 0.6078 \\
\hline 11. I have been coughing & 0.71 & 0.71 & 0.00 & $-0.11,0.10$ & 0.9354 \\
\hline 12. I am bothered by fever & 0.13 & 0.15 & -0.02 & $-0.07,0.04$ & 0.5989 \\
\hline $\begin{array}{l}\text { 13. I am able to work (includes work from } \\
\text { home) }\end{array}$ & 1.92 & 1.92 & -0.01 & $-0.15,0.14$ & 0.9391 \\
\hline 14. I have blood in my urine & 0.03 & 0.04 & -0.02 & $-0.04,0.00$ & 0.1369 \\
\hline 15. I am sleeping well & 2.36 & 2.29 & 0.06 & $-0.07,0.19$ & 0.3543 \\
\hline \multicolumn{6}{|c|}{$\begin{array}{l}\text { Abbreviations: } \mathrm{Cl}=\text { confidence interval; FKSI-DRS }=\text { Functional Assessment of Cancer Therapy-Kidney Cancer Symptom Index-disease-related symptoms subscale; FKSI- } 15=\text { Functional } \\
\text { Assessment of Cancer Therapy Kidney Symptom Index- } 15 \text {. Analysis based on repeated measures mixed-effects model with terms for treatment, time, and treatment-by-time, with baseline as } \\
\text { covariate and time assumed continuous. Means are based on observed scores } 0-4 \text {, where } 0=\text { not at all, } 1=\text { a little bit, } 2=\text { somewhat, } 3=\text { quite a bit, and } 4=\text { very much. A larger score may } \\
\text { correspond to a better or worse health state depending on the item question. FKSI-DRS consists of questions } 1,3,4,5,6,8,11,12 \text {, and } 14 \text { of the FKSI-15. }\end{array}$} \\
\hline
\end{tabular}

repeated measures analysis (Table 2). As for FKSI-15, there was no significant treatment-by-time interaction $(P=0.8024)$, indicating no difference in the course of the treatment effect over the cycles. Most scores were similar between treatments across the nine items of the FKSI-DRS. Figure 3 depicts the observed mean difference between treatments in degree of bother with side effects. Patterns in FKSI-DRS scores in subgroups by prior treatment (sunitinib vs cytokine therapy) and MSKCC risk group were similar to those reported above for FKSI-15.

EQ-5D assessments. Similar to the FKSI results, observed EQ-5D means were similar until EOT, after which there was a drop when patients typically experienced disease progression. There was no statistically significant difference between axitinib and sorafenib in EQ-5D index scores in the mixed-effects model; (difference, 0.02; $P=0.1903$; Table 2) or in the interaction between treatment and time $(P=0.8048)$.

In the EQ-5D health status profile, the proportion of patients with no problems with mobility through cycle 12 was $\sim 10 \%$ higher at every cycle in the axitinib vs the sorafenib arm and was never below $57 \%$ and $49 \%$ of respondents, respectively. The proportion of patients with no problem with pain/discomfort was similar (30-40\%) while on treatment throughout the study for both treatment arms, as was the proportion of patients with no problem with anxiety/depression (50-60\%).

\section{DISCUSSION}

This study summarises patient-reported outcomes from a randomised phase III study that directly compared axitinib with sorafenib in patients with mRCC following failure of a prior systemic therapy. Efficacy results (reported elsewhere Rini et al, 2011) demonstrated that axitinib treatment resulted in significantly longer PFS compared with sorafenib and the analysis of the composite end point of TTD (defined as a decrease in quality of life (worsening of FKSI-15 score), progression or death; see Rini et al (2011) for further details) demonstrated a statistically significant advantage for axitinib: $\mathrm{HR}=0.829,95 \%$ confidence interval $(\mathrm{CI})$ : $0.701,0.981$; one-sided $P=0.014$. Similarly, a $16 \%$ risk reduction in the TTD FKSI-DRS composite end point was observed for axitinib vs sorafenib $(\mathrm{HR}=0.838,95 \%$ CI: 0.707, 0.993; one-sided $P=0.0203$ ), highlighting that the delay in disease progression was accompanied by minimal toxicity or worsening of symptoms. These results confirm those of the two single-arm phase II studies in patients with mRCC (Trask et al, 2008; Rini et al, 2009).

This report focuses on patient-reported kidney-specific symptoms and functional data. Treatment with axitinib was associated with comparable outcomes to sorafenib, as demonstrated by similar FKSI-15 scores while on treatment. When patients experienced disease progression at EOT, FKSI scores worsened, revealing the impact that progression had on patient HRQoL and also, the value of delaying progression. Scores at 28-days post endof-treatment were also measured, and revealed a slight improvement (of similar magnitude in both arms) compared with EOT. However, this was likely because responders were healthier than those who did not complete the forms, as the end-of-treatment scores for responders were similar to their day 28 scores.

Of note, the baseline scores of patients in this study were comparable to the general US population (Butt et al, 2012) and, as such, it would be unrealistic to expect an improvement in symptoms/quality of life as can be observed, for example, in lung cancer, where patients are very symptomatic at baseline. In the present study, patients were able to 'maintain' symptom control while on treatment with both agents; however, when their disease progressed at EOT, there was a meaningful worsening of patientreported outcomes. In essence, this reflects that patients receiving VEGF TKI treatment (whether sorafenib or axitinib) manage to 


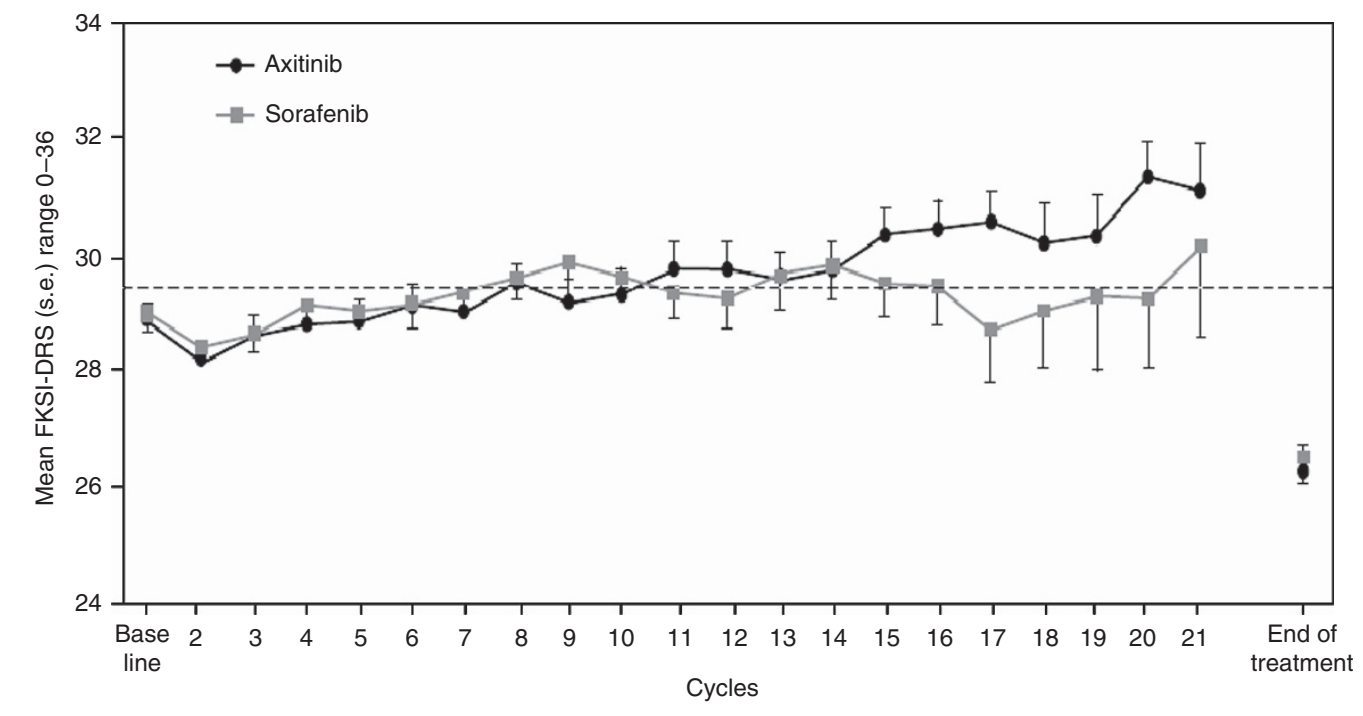

\begin{tabular}{|c|c|c|c|c|c|c|c|c|c|c|c|c|c|c|c|c|c|c|c|c|c|c|}
\hline Axitinib & 346 & 319 & 279 & 257 & 238 & 213 & 206 & 177 & 163 & 146 & 122 & 110 & 92 & 81 & 61 & 52 & 47 & 36 & 29 & 20 & 15 & 163 \\
\hline Sorafenib & 341 & 295 & 244 & 220 & 202 & 178 & 157 & 135 & 117 & 96 & 85 & 70 & 58 & 54 & 38 & 34 & 28 & 22 & 14 & 12 & 7 & 191 \\
\hline
\end{tabular}

Figure 2. Mean FKSI-DRS scores over the course of the study. Dotted line represents US population mean. FKSI-DRS, Functional Assessment of Cancer Therapy-Kidney Cancer Symptom Index-disease-related symptoms subscale; s.e., standard error.

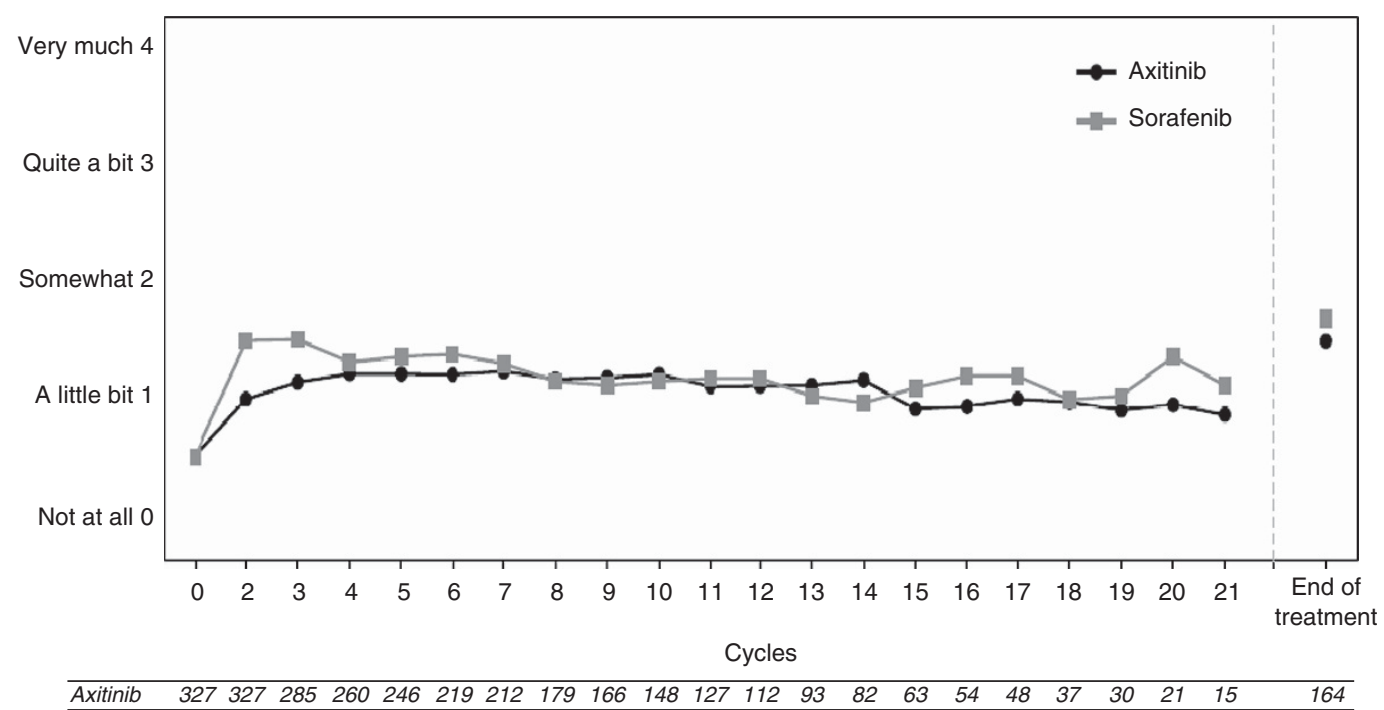

Figure 3. Response to individual FKSI question, 'I am bothered by side effects of treatment.' EOT, end of treatment; FKSI, Functional Assessment of Cancer Therapy-Kidney Cancer Symptom Index.

maintain a relatively low symptom burden, comparable to their pre-treatment condition. This declined significantly at EOT, suggesting that VEGF TKI therapy that delays progression longer would have better value than one associated with a shorter progression-free interval. Understanding the value of PFS is increasingly important because demonstrating an overall survival benefit can be challenging in tumours such as mRCC, where survival post progression is long (Amir et al, 2012; Fallowfield and Fleissig, 2012), and it has been suggested delay of symptoms can be just as important as overall survival (Amir et al, 2012).

The FKSI-DRS measures intend to assess disease-related symptoms (Cella et al, 2007). In oncology clinical trials, symptoms represent the most proximal outcome of treatment for patients with advanced RCC and are most likely to detect differences between treatments. Information on patient-reported symptoms and functioning, combined with clinical end points, can assist patients and physicians in selecting the most effective treatments.
Given the availability of new therapies for treating mRCC, patients need to understand the trade-off between PFS and treatmentrelated toxicity. In the present study, most scores across the nine items of the FKSI-DRS were similar among patients treated with axitinib or sorafenib.

It is difficult to systematically compare results of axitinib studies with those of other approved second-line treatments for advanced RCC (Bukowski et al, 2007; Eisen et al, 2008; Beaumont et al, 2011) owing to differences in the FKSI questionnaire versions and analyses used, patient populations studied in the second-line setting and compliance with patient-reported data collection. This is the first trial comparing two VEGFR-TKI agents head-to-head in the second-line mRCC setting. A number of studies have used placebo or IFN- $\alpha$ as comparators. For example, in a recent study (Beaumont et al, 2011) in patients with advanced RCC, there were no statistically significant differences in FKSI-DRS scores in longitudinal analyses for everolimus compared with placebo. 
Similar findings were observed in a study of sorafenib in advanced RCC (Bukowski et al, 2007), which reported that there were no differences between sorafenib and placebo in mean scores for either the Functional Assessment of Cancer Therapy-General or the FKSI-10. Based on the results of the present study, axitinib has comparable HRQoL outcomes and better PFS compared with sorafenib in patients with advanced RCC, supported by the previously reported $16-17 \%$ (statistically significant) decrease in the composite TTD end point comprises risk of progression, death or worsening of FKSI scores (Rini et al, 2011). Several limitations should be considered when interpreting the results of this analysis. The open-label trial design could be considered as a limitation because investigators and patients could be biased in their selfreported assessments based on treatment expectations. Although open-label, the study had an active comparator; therefore, the potential for bias is reduced compared with a placebo-controlled study. Furthermore, all analyses were pre-specified secondary end points of the AXIS trial. Differential dropout rates were observed. As patients in the sorafenib arm had higher rates of study discontinuation, we conducted additional statistical modelling to address this potential imbalance and found similar results. However, missing data complicate interpretation of patient-reported outcomes, and the true effect of sorafenib on HRQoL may not have been assessed. Also, the inclusion of other questionnaires targeting an expanded list of side effects may have permitted more information to be collected about this class of agent.

In summary, this clinical trial compared two VEGFR TKIs as second-line therapy for mRCC. One goal in mRCC treatment is to maintain patient symptoms or HRQoL for as long as possible, and thereby delay worsening. Clearly, when patients are assessed at EOT, their FKSI scores are worse than they were while on treatment. This is likely to be related to tumour progression, although the impact on HRQoL of factors such as unresolved adverse events, accumulating toxicity and emotional response cannot be ruled out. Given that disease-related symptoms and HRQoL are better when patients are on treatment and progression-free and that patients receiving axitinib have significantly longer PFS compared with sorafenib, patients who receive axitinib are more likely to have longer symptom 'control' that is not offset by a worsening of patient-reported outcomes. Patient-reported outcomes provide clinicians and patients with supplemental information on the overall impact of disease-related symptoms, progression and toxicity on functioning and well-being and can help patients and their providers discuss treatment options with more information than toxicity and PFS alone.

\section{ACKNOWLEDGEMENTS}

This study was sponsored by Pfizer Inc. Medical writing support was provided by Dennis Revicki, PhD, at United Biosource Corporation and Helen Jones, PhD, at UBC Scientific Solutions and was funded by Pfizer Inc.

\section{CONFLICT OF INTEREST}

DC has served as a consultant for and received research funding from Pfizer, AVEO, Bayer, GlaxoSmithKline, and Novartis. BE has received honoraria from AVEO, Bayer, GlaxoSmithKline, Novartis, and Pfizer. BRi has served as a consultant for and received research funding from Pfizer. CC, HB, JT, Bro, and SK are employees of and shareholders in Pfizer Inc. RM has served as a consultant for Pfizer.

\section{REFERENCES}

Amir E, Seruga B, Kwong R, Tannock IF, Ocana A (2012) Poor correlation between progression-free and overall survival in modern clinical trials: are composite endpoints the answer? Eur J Cancer 48: 385-388.

Beaumont JL, Butt Z, Baladi J, Motzer RJ, Haas T, Hollaender N, Kay A, Cella D (2011) Patient-reported outcomes in a phase III Study of everolimus versus placebo in patients with metastatic carcinoma of the kidney that has progressed on vascular endothelial growth factor receptor tyrosine kinase inhibitor therapy. Oncologist 16: 632-640.

Bukowski R, Cella D, Gondek K, Escudier B (2007) Effects of sorafenib on symptoms and quality of life: results from a large randomized placebocontrolled study in renal cancer. Am J Clin Oncol 30: 220-227.

Butt Z, Peipert J, Webster K, Chen C, Cella D (2012) General population norms for the Functional Assessment of Cancer Therapy-Kidney Symptom Index (FKSI). Cancer 119: 429-437.

Cella D (2009) Quality of life in patients with metastatic renal cell carcinoma: the importance of patient-reported outcomes. Cancer Treat Rev 35: 733-737.

Cella D, Yount S, Brucker PS, Du H, Bukowski R, Vogelzang N, Bro WP (2007) Development and validation of a scale to measure disease-related symptoms of kidney cancer. Value Health 10: 285-293.

Cella D, Yount S, Du H, Dhanda R, Gondek K, Langefeld K, George J, Bro WP, Kelly C, Bukowski R (2006) Development and validation of the Functional Assessment of Cancer Therapy-Kidney Symptom Index (FKSI). J Support Oncol 4: 191-199.

Eisen T, Oudard S, Szczylik C, Gravis G, Heinzer H, Middleton R, Cihon F, Anderson S, Shah S, Bukowski R, Escudier B (2008) Sorafenib for older patients with renal cell carcinoma: subset analysis from a randomized trial. J Natl Cancer Inst 100: 1454-1463.

Escudier B, Eisen T, Stadler WM, Szczylik C, Oudard S, Siebels M, Negrier S, Chevreau C, Solska E, Desai AA, Rolland F, Demkow T, Hutson TE, Gore M, Freeman S, Schwartz B, Shan M, Simantov R, Bukowski RM (2007a) Sorafenib in advanced clear-cell renal-cell carcinoma. N Engl J Med 356: $125-134$.

Escudier B, Eisen T, Stadler WM, Szczylik C, Oudard S, Staehler M, Negrier S, Chevreau C, Desai AA, Rolland F, Demkow T, Hutson TE, Gore M, Anderson S, Hofilena G, Shan M, Pena C, Lathia C, Bukowski RM (2009) Sorafenib for treatment of renal cell carcinoma: Final efficacy and safety results of the phase III treatment approaches in renal cancer global evaluation trial. J Clin Oncol 27: 3312-3318.

Escudier B, Pluzanska A, Koralewski P, Ravaud A, Bracarda S, Szczylik C, Chevreau C, Filipek M, Melichar B, Bajetta E, Gorbunova V, Bay JO, Bodrogi I, Jagiello-Gruszfeld A, Moore N (2007b) Bevacizumab plus interferon alfa-2a for treatment of metastatic renal cell carcinoma: a randomised, double-blind phase III trial. Lancet 370: 2103-2111.

Fallowfield LJ, Fleissig A (2012) The value of progression-free survival to patients with advanced-stage cancer. Nat Rev 9: 41-47.

Gupta K, Miller JD, Li JZ, Russell MW, Charbonneau C (2008) Epidemiologic and socioeconomic burden of metastatic renal cell carcinoma (mRCC): a literature review. Cancer Treat Rev 34: 193-205.

Harding G, Cella D, Robinson Jr. D, Mahadevia PJ, Clark J, Revicki DA (2007) Symptom burden among patients with renal cell carcinoma (RCC): content for a symptom index. Health Qual Life Outcomes 5: 34.

Hedeker D, Gibbons R (2006) Longitudinal Data Analysisedn. John Wiley \& Sons: Hoboken.

Heng DY, Xie W, Regan MM, Warren MA, Golshayan AR, Sahi C, Eigl BJ, Ruether JD, Cheng T, North S, Venner P, Knox JJ, Chi KN,

Kollmannsberger C, McDermott DF, Oh WK, Atkins MB, Bukowski RM, Rini BI, Choueiri TK (2009) Prognostic factors for overall survival in patients with metastatic renal cell carcinoma treated with vascular endothelial growth factor-targeted agents: results from a large, multicenter study. J Clin Oncol 27: 5794-5799.

Hu-Lowe DD, Zou HY, Grazzini ML, Hallin ME, Wickman GR, Amundson K, Chen JH, Rewolinski DA, Yamazaki S, Wu EY, McTigue MA, Murray BW, Kania RS, O'Connor P, Shalinsky DR, Bender SL (2008) Nonclinical antiangiogenesis and antitumor activities of axitinib (AG-013736), an oral, potent, and selective inhibitor of vascular endothelial growth factor receptor tyrosine kinases 1, 2, 3. Clin Cancer Res 14: 7272-7283.

Hudes G, Carducci M, Tomczak P, Dutcher J, Figlin R, Kapoor A, Staroslawska E, Sosman J, McDermott D, Bodrogi I, Kovacevic Z, Lesovoy V, Schmidt-Wolf IG, Barbarash O, Gokmen E, O'Toole T, Lustgarten S, 
Moore L, Motzer RJ (2007) Temsirolimus, interferon alfa, or both for advanced renal-cell carcinoma. N Engl J Med 356: 2271-2281.

Kind P (1996) The EuroQol Instrument: An Index of Health-Related Quality of Life. Quality of Life and Pharmacoeconomics in Clinical Trials. In Spilker B (ed.) 2nd edn. Lippicott-Raven: Philadephia.

Lam JS, Belldegrun AS, Figlin RA (2004) Advances in immune-based therapies of renal cell carcinoma. Expert Rev Anticancer Ther 4: 1081-1096.

Linehan WM, Zbar B (2004) Focus on kidney cancer. Cancer Cell 6: 223-228.

Motzer RJ, Bacik J, Schwartz LH, Reuter V, Russo P, Marion S, Mazumdar M (2004) Prognostic factors for survival in previously treated patients with metastatic renal cell carcinoma. J Clin Oncol 22: 454-463.

Motzer RJ, Escudier B, Oudard S, Hutson TE, Porta C, Bracarda S, Grunwald V, Thompson JA, Figlin RA, Hollaender N, Kay A, Ravaud A (2010) Phase 3 trial of everolimus for metastatic renal cell carcinoma: final results and analysis of prognostic factors. Cancer 116: 4256-4265.

Motzer RJ, Escudier B, Oudard S, Hutson TE, Porta C, Bracarda S, Grunwald V, Thompson JA, Figlin RA, Hollaender N, Urbanowitz G, Berg WJ, Kay A, Lebwohl D, Ravaud A (2008) Efficacy of everolimus in advanced renal cell carcinoma: a double-blind, randomised, placebo-controlled phase III trial. Lancet 372: 449-456.

Motzer RJ, Hutson TE, Tomczak P, Michaelson MD, Bukowski RM, Rixe O, Oudard S, Negrier S, Szczylik C, Kim ST, Chen I, Bycott PW, Baum CM, Figlin RA (2007) Sunitinib versus interferon alfa in metastatic renal-cell carcinoma. N Engl J Med 356: 115-124.

Rini BI, Escudier B, Tomczak P, Kaprin A, Szczylik C, Hutson TE, Michaelson MD, Gorbunova VA, Gore ME, Rusakov IG, Negrier S, Ou YC, Castellano D, Lim HY, Uemura H, Tarazi J, Cella D, Chen C, Rosbrook B, Kim S, Motzer RJ (2011) Comparative effectiveness of axitinib versus sorafenib in advanced renal cell carcinoma (AXIS): a randomised phase 3 trial. Lancet 378: 1931-1939.

Rini BI, Wilding G, Hudes G, Stadler WM, Kim S, Tarazi J, Rosbrook B, Trask PC, Wood L, Dutcher JP (2009) Phase II study of axitinib in sorafenib-refractory metastatic renal cell carcinoma. J Clin Oncol 27: 4462-4468.
Rixe O, Bukowski RM, Michaelson MD, Wilding G, Hudes GR, Bolte O, Motzer RJ, Bycott P, Liau KF, Freddo J, Trask PC, Kim S, Rini BI (2007) Axitinib treatment in patients with cytokine-refractory metastatic renalcell cancer: a phase II study. Lancet Oncol 8: 975-984.

Rubin D (1976) Inference and missing data. Biometrika 72: 359-364.

Singer J, Willett J (2003) Applied Longitudinal Data Analysis: Modeling Change and Event Occurrenceedn. Oxford University Press: New York.

Sternberg CN, Davis ID, Mardiak J, Szczylik C, Lee E, Wagstaff J, Barrios CH, Salman P, Gladkov OA, Kavina A, Zarba JJ, Chen M, McCann L, Pandite L, Roychowdhury DF, Hawkins RE (2010) Pazopanib in locally advanced or metastatic renal cell carcinoma: results of a randomized phase III trial. $J$ Clin Oncol 28: 1061-1068.

Therasse P, Arbuck SG, Eisenhauer EA, Wanders J, Kaplan RS, Rubinstein L, Verweij J, Van Glabbeke M, van Oosterom AT, Christian MC, Gwyther SG (2000) New guidelines to evaluate the response to treatment in solid tumors. European Organization for Research and Treatment of Cancer, National Cancer Institute of the United States, National Cancer Institute of Canada. J Natl Cancer Inst 92: 205-216.

Trask PC, Bushmakin AG, Cappelleri JC, Bycott P, Liau K, Kim S (2008) Health-related quality of life during treatment for renal cell carcinoma: results from a phase II study of axitinib. Acta Oncol (Stockholm, Sweden) 47: 843-851.

Troxel AB, Fairclough DL, Curran D, Hahn EA (1998) Statistical analysis of quality of life with missing data in cancer clinical trials. Stat Med 17: 653-666.

Wagner LI, Wenzel L, Shaw E, Cella D (2007) Patient-reported outcomes in phase II cancer clinical trials: lessons learned and future directions. J Clin Oncol 25: 5058-5062.

This work is published under the standard license to publish agreement. After 12 months the work will become freely available and the license terms will switch to a Creative Commons AttributionNonCommercial-Share Alike 3.0 Unported License. 